\title{
Volatility Clustering at a Sector Level in the Chinese Equity Market
}

\author{
Gerardo "Gerry" Alfonso Perez ${ }^{1}$ \\ ${ }^{1}$ Universidad de Granada, Granada, Spain \\ Correspondence: Gerardo “Gerry” Alfonso Perez, Universidad de Granada, Granada, Spain.
}

Received: June 7, 2018

doi:10.5430/ijfr.v9n3p103
Online Published: July 2, 2018

URL: https://doi.org/10.5430/ijfr.v9n3p103

\begin{abstract}
The issue of volatility clustering i.e., if periods of high volatility on stocks returns are typically followed by other periods of high volatility and vice versa, is analysed in this article at a sector level for the Chinese stock market. This analysis was performed with daily returns for the period from 2008 to 2017. When the entire dataset is analysed the statistical tests are rather consistent indicating that there is volatility clustering for all the major nine sectors (basic materials, communications, consumer cyclical, consumer non-cyclical, energy financial, industrial, technology and utilities). However, when each year is analysed independently the results are much more mixed with some sectors, such as technology companies, that could a priori look as a prime candidate for volatility clustering having less years with such feature present that other sectors such as for instance basic materials. The issue of volatility clustering at a sector level is of clear interest and can be used as another tool to optimize portfolio allocations. It is interesting to see that volatility clustering seems to be present when the statistical tests are performed over long periods of time but less so when the timeframe is shortened.
\end{abstract}

Keywords: China, volatility clustering, portfolio management

\section{Introduction}

The volatility clustering concept at its core is relatively simple. The idea is that big volatility in returns is typically followed by additional big volatility while small volatility in returns is followed by small volatility in returns in what could be described as some type of inertia in the market. (Mandelbrot, 1963) is one of the first and more frequently quoted papers in the topic of volatility clustering of assets returns. In that paper the author developed a solid mathematical foundation for understanding this issue moving away from the assumption of the returns following a normal distribution. (Mandelbrot, 1963) used the example of cotton prices. Volatility clustering has been found in many asset returns such as foreign exchange (Andersen and Bollerslev, 1997), real estate (Pinte and Fuerst, 2014) as well as stock returns. The basic concept is rather simple and could be expressed as the idea that periods of high volatility tend to be followed by periods of high volatility and vice versa. In a mathematical way this can be expressed as in equation 1, see for instance (Cont, 2005) or for a more detailed analysis (Granger and Machina, 2006):

$$
\sigma_{T}^{2}=a_{0}+a_{1} \sigma_{T-1}^{2}+a_{2} \varepsilon_{T}^{2}
$$

There is abundant literature analyzing this concept in the context of the U.S. stock market, such as (Andersen, 1997), (Cont, 2005), (Lux, 2000), (Dudukovic, 2014) to cite some. Volatility clustering has been identified in markets as diverse as India (Karunanithy and Ramachandran, 2015), Macedonia (Ivanoski et al., 2015) and South Africa (Niyitegeka and Tewari, 2013). The concept of volatility clustering has also attracted the attention of many practitioners, particularly regarding applications of the concept on derivatives (Gatheral, 2002). Volatility estimates are an integral part on derivatives pricing and it is also a proxy for risk so it is a crucial factor in the stock market (cash equities) (Bollerslev, Chou and Kroner, 1992) (Crouhy and Rockinger, 1997), (Ping, Peijie and Aying, 2005), (Balaban andar, 2006). In this context the term cash equities refers to trading directly on stocks rather than using derivatives.

In this article I analyze the topic of volatility clustering, at a sector level, in the mainland China equity market. The Chinese equity market has expanded at a very considerable rate over the last few decades and it is currently one of the largest markets in the world. In this context it seems reasonable to try to analyze at a more granular level (sector) the issue of volatility clustering to try to see if there are meaningful differences among different types of Chinese stocks. This article focuses on Chinese A-shares. A-shares are the predominant type of stocks in the mainland China 
stock market, listed either in the Shanghai or Shenzhen Stock Exchange. In this article B-shares are excluded from the analysis as they are an equity instrument targeting foreign investors, rather than local ones. Moreover the relative importance of B-shares has gradually decreased with no new listings in recent years. By market capitalization the A-share market is much larger than the B-share one.

The importance of the domestic Chinese equity market (A-share market) in the global financial markets is likely to increase in the future with developments in recent years making it more accessible to overseas investors, such as the Hong Kong-Shanghai Connect or the Hong Kong-Shenzhen Connect programs that allow, under some restrictions, reciprocal access to the onshore Chinese equity market to investors located in Hong Kong and vice versa. Another recent development is the inclusion of Chinese A-shares into the MSCI Emerging Markets Index, which is expected to bring large inflows of foreign capital into the Chinese domestic equity market. For more detailed on the implementation of the inclusion of A-shares into the MSCI Emerging Markets index the reader is directed to (MSCI 2018). Given the increasingly importance of this market it seemed interesting analyzing at a relatively granular level (sector level) the existence of volatility clustering.

There are some very interesting articles regarding stock volatility in the Chinese market. For instance, (Friedmann and Sanddorf-Khole 2002) found that return volatility in China is significantly impacted by the large amount of non-trading days around the Chinese New Year holiday break. (Fabozzi et al. 2004) determined that there was no volatility transmission between the Shanghai and the Shenzhen Stock Exchange. Another interesting article is (Tripathi and Chaushary 2016). (Tripathi and Chaushary 2016) did not find evidence of volatility clustering in the Chinese stock market for monthly returns. Interestingly (Cheteni 2016) did find evidence of volatility clustering in the Chinese market. There are some methodological differences between (Tripathi and Chaushary 2016) and (Cheteni 2016). (Tripathi and Chaushary 2016) used the Shanghai Stock Exchange Composite Index and the Shenzhen Stock Exchange Composite Index as the raw data for the analysis while (Cheteni 2016) used the Shanghai Stock Exchange Composite Index only. Both of those indexes include B-shares, in fact both indexes include all the A-shares and all the B-shares while in this article I used A-share data only and at the company level rather than relying on indexes. This was necessary in order to build the nine different sector indexes. It should be noted however that the B-share market is rather small compared to the A-share market and therefore it is likely that it has a relatively small impact on the outcome of the analysis. According to data from Bloomberg the total market capitalization of the B-share market was approximately around $2.5 \%$ of the market capitalization of the A-share market as of end of 2017.

\section{Method}

Daily closing stock prices for constituents companies of the CSI 300 index, figure 1, were obtained from the data provider Bloomberg for the period from January 2008 to December 2017 and such closing levels were transformed into returns. The companies were grouped attending the Bloomberg level 1 sector classification into one of the following nine categories: 1) basic materials, 2) communications, 3) consumer cyclical, 4) consumer non-cyclical, 5) energy, 6) financial, 7) industrial, 8) technology and 9) utilities. Equal weight indexes were built for each of the nine indexes, figure 2 . This broad sector classification (level 1) is frequently used by fund managers as the starting point in the sector allocation. There are other levels of sector classification, such as level 2, which has several more classification levels. However, the more granular the sector classification becomes the less amount of companies falling in each sector that there are, making the construction of a representative portfolio challenging. This was the main reason behind choosing the level 1 classification rather than the level 2 classification. It is also acknowledged that there is some level of subjectivity when categorizing companies into different sectors. The reason behind using the classification of a well-known data provider like Bloomberg was to try to reduce this subjectivity. Companies with long or frequent trading suspensions were excluded from the indexes. This is one of the major limitations of the data as voluntary and involuntary trading suspensions are relatively frequent in the mainland China market. Daily closing prices, for short trading suspensions periods, were interpolated. Stocks with short track record were also excluded from the indexes. A reasonably comparable number of stocks was attempted to be included in each sector but it should be noted that some sectors, such as energy, are composed of a hand full of stocks with typically large market capitalization. A representative portfolio was then built for each sector, using the previously mentioned results. No additional criteria were used when building the representative portfolios. The portfolios were rebalanced yearly.

In order to test the existence of volatility clustering in the sector indexes a Ljung-Box Q test (Stoffer 1992) with 5 and 10 lags was performed. This was done using the entire time series (2008-2017), table 1, as well as for each year independently, table 2 . The null hypothesis of this test is that there is no volatility clustering present on the data. All the statistical tests were performed in Matlab. The Ljung-Box Q test can be defined (equation 2), as follows (Ljung and Box 1978): 


$$
\mathrm{LB}=\mathrm{n}(\mathrm{n}+2) \sum_{j} \frac{\rho_{j}^{2}}{n-j}
$$

The Ljung-Box Q test is a frequent test in the context of volatility clustering analysis with several articles such as (Stoffer 1992) using it.

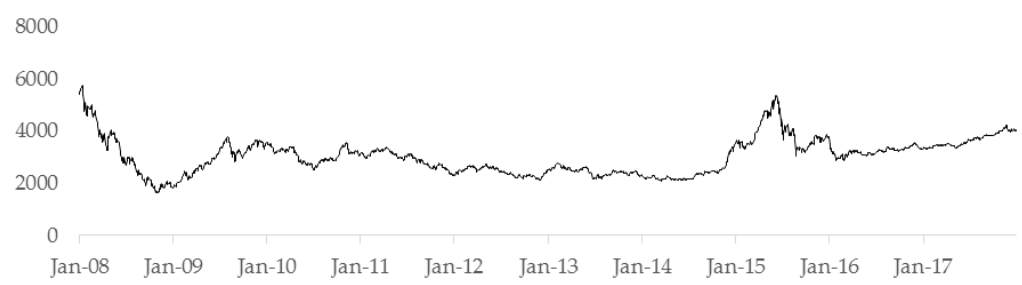

Figure 1. CSI 300 Index
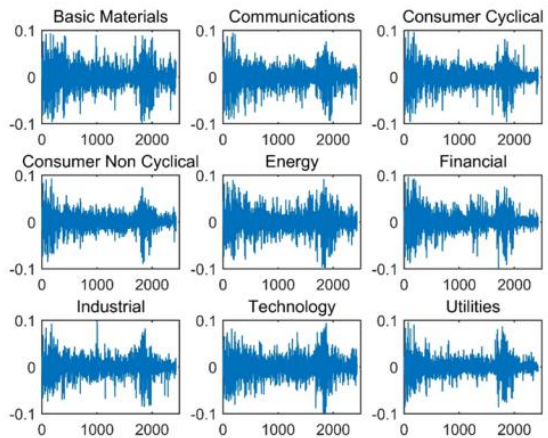

Figure 2. Daily returns of the sector indexes

Table 1. Ljung test (5 and 10 lags) for the 2008-2017 period

\begin{tabular}{lllll}
\hline Sector & $\mathbf{h}$ & $\mathbf{h}$ & $\mathbf{p}$ & $\mathbf{p}$ \\
\hline Basic materials & 1 & 1 & 0.000 & 0.000 \\
Communications & 1 & 1 & 0.000 & 0.000 \\
Consumer cyclical & 1 & 1 & 0.000 & 0.000 \\
Consumer non-cyclical & 1 & 1 & 0.000 & 0.000 \\
Energy & 1 & 1 & 0.000 & 0.000 \\
Financial & 1 & 1 & 0.000 & 0.000 \\
Industrial & 1 & 1 & 0.000 & 0.000 \\
Technology & 1 & 1 & 0.000 & 0.000 \\
Utilities & 1 & 1 & 0.000 & 0.000 \\
\hline
\end{tabular}

\section{Results}

When the entire dataset is analyzed (2008-2017) the Ljung-Box Q test is consistent for all the sectors indicating that there is volatility clustering present (table 1). For the individual years (table 2) the results are much more complex with three years of predominantly volatility clustering (2009, 2015 and 2016), five years of predominantly no volatility clustering $(2008,2010,2011,2013$ and 2017) and mixed results in the other years. The technology sector which is frequently considered a volatile one prone to rallies and corrections yielded interesting results with volatility clustering, according to the formal statistical test, present in only four out of the ten years analyzed. Volatility clustering was detected in the basic materials sector (mining and commodity related stocks) for six of the ten years 
studied using the previously mentioned Ljung-Box test. This was the most frequent volatility clustering detected among all sectors. The sectors with less volatility clustering detected were communication and financial stocks, with three years each. It appears that the relationship between sectors and the volatility clustering might be more complex than what it would appear a priori. It is important to remark that volatility clustering does not necessarily mean that there is high volatility in the sector compared to the overall market but just that period of high volatility tend to be followed by periods of high volatility and vice versa.

\section{Discussion}

The stock market in mainland China seems to present volatility clustering at a sector level when analyzing long time series of stock returns (2008-2017). For shorter time periods, such as calendar years, the results are much more mixed with significant differences among major sectors. The data seems to contradict the assumption that perceived volatile sectors, such as technology related shares, should frequently present volatility clustering. Similarly, other sectors that are not perceived as particularly volatile, such as basic materials, seem to have volatility clustering more frequently. This might have important practical applications has a one year period is typically the length over which many fund managers have their performance assessed and it is hence a relevant time window.

Analyzing volatility clustering at the sector level might provide useful information for practitioners and academics trying to identified trends in the market. If there is volatility persistence during a period of market correction then it might be prudent to reduce exposure to that asset while if there is no statistical reliable evidence of volatility clustering then using such technique to increase or decrease exposure is unlikely to enhanced risk returns. Volatility clustering is just one of the many tools available for market trend analysis but it could prove useful when applied in combination of other techniques. It should also be noted that reducing market exposure i.e., owning a proportionally lower amount of shares (more cash and cash equivalents) likely decreases the risk in the portfolio but it also decreases the potential upside so investing strategies that use this approach (reducing exposure when the forecast for volatility is high) are relatively conservative strategies.

Table 2. Ljung test results per year, 5 and 10 lags (h5, h10, p5, p10)

\begin{tabular}{cccccccccc}
\hline Year & $\begin{array}{c}\text { Basic } \\
\text { materials }\end{array}$ & Communications & $\begin{array}{c}\text { Consumer } \\
\text { cyclical }\end{array}$ & $\begin{array}{c}\text { Consumer, } \\
\text { non-cyclical }\end{array}$ & Energy & Financial & Industrial & Technology & Utilities \\
\hline 2008 & $(0,0,0.4640,0.4346)$ & $(0,0,0.9426,0.7519)$ & $(0,0,0.6636,0.5707)$ & $(0,0,0.9569,0.9777)$ & $(0,0,0.4339,0.8417)$ & $(0,0,0.9861,0.2052)$ & $(0,0,0.9510,0.9097)$ & $(0,1,0.6170,0.0282)$ & $(1,0,0.0216,0.1205)$ \\
2009 & $(1,1,0.0019,0.0018)$ & $(1,1,0.0016,0.0003)$ & $(1,1,0.0000,0.0000)$ & $(1,1,0.0001,0.0000)$ & $(0,1,0.1351,0.0013)$ & $(0,1,0.0754,0.0059)$ & $(1,1,0.0103,0.0088)$ & $(1,1,0.0010,0.0060)$ & $(1,1,0.0000,0.0000)$ \\
2010 & $(1,1,0.0030,0.0003)$ & $(0,0,0.4275,0.1332)$ & $(0,0,0.3677,0.6951)$ & $(1,1,0.0002,0.0012)$ & $(0,0,0.4140,0.5837)$ & $(0,0,0.2657,0.6436)$ & $(0.0 .0 .4556,0.4131)$ & $(0,0,0.3920,0.1535)$ & $(0,0,0.6472,0.7906)$ \\
2011 & $(0,0,0.6898,0.5488)$ & $(0,0,0.9244,0.8901)$ & $(0,0,0.9418,0.2889)$ & $(0,0,0.0773,0.1621)$ & $(0,0,0.9098,0.4725)$ & $(0,0,0.5946,0.4824)$ & $(0,0,0.6274,0.8040)$ & $(0,0,0.9277,0.9946)$ & $(0,0,0.6688,0.6868)$ \\
2012 & $(1,0,0.0427,0.0593)$ & $(0,0,0.5115,0.2325)$ & $(0,0,0.2019,0.0860)$ & $(1,1,0.0001,0.0001)$ & $(0,0,0.4478,0.0833)$ & $(0,1,0.7902,0.0008)$ & $(0,0,0.0933,0.1114)$ & $(1,1,0.0046,0.0001)$ & $(0,0,0.7972,0.8439$ \\
2013 & $(0,0,0.5283,0.1446)$ & $(0,0,0.6011,0.8143)$ & $(0,0,0.1667,0.2827)$ & $(0,0,0.1203,0.3080)$ & $(1,1,0.0050,0.0223)$ & $(0,0,0.8852,0.9906)$ & $(0,1,0.0966,0.0032)$ & $(0,0,0.5672,0.3555)$ & $(0,0,0.7511,0.2580)$ \\
2014 & $(1,1,0.0002,0.0007)$ & $(0,1,0.2712,0.0000)$ & $(0,0,0.8919,0.9953)$ & $(0,0,0.5177,0.9049)$ & $(1,1,0.0001,0.0001)$ & $(1,1,0.0000,0.00000)$ & $(1,1,0.0066,0.0003)$ & $(0,0,0.3547,0.0911)$ & $(1,1,0.0000,0.0000)$ \\
2015 & $(1,1,0.0000,0.0000)$ & $(1,1,0.0000,0.0000)$ & $(1,1,0.0000,0.0000)$ & $(1,1,0.0000,0.0000)$ & $(1,1,0.0001,0.0001)$ & $(1,1,0.0000,0.0000)$ & $(1,1,0.0000,0.0000)$ & $(1,1,0.0000,0.0000)$ & $(1,1,0.0000,0.0000)$ \\
2016 & $(1,1,0.0000,0.0000)$ & $(1,1,0.0000,0.0000)$ & $(1,1,0.0006,0.0047)$ & $(1,1,0.0000,0.0000)$ & $(1,1,0.0000,0.0000)$ & $(1,1,0.0000,0.0000)$ & $(1,1,0.0000,0.0000)$ & $(1,1,0.0025,0.0000)$ & $(1,1,0.0000,0.0000)$ \\
2017 & $(0,1,0.0851,0.0001)$ & $(0,0,0.1082,0.4536)$ & $(1,0,0.0159,0.1010)$ & $(0,0,0.7301,0.9303)$ & $(1,1,0.0028,0.0000)$ & $(0,0,0.7907,0.5202)$ & $(0,0,0.9744,0.9981)$ & $(0,0,0.5897,0.2708)$ & $(0,0,0.0588,0.2625)$ \\
\hline
\end{tabular}

\section{References}

Andersen, T., \& Bollerslev, T. (1997). Intraday periodicity and volatility persistence in financial markets. Journal of Empirical Finance, 4. https://doi.org/10.1016/S0927-5398(97)00004-2

Balaban, E., \& Bayar, A. (2006). Stock returns and volatility: empirical evidence from fourteen countries. Applied Economic Letter, 12.

Bollerslev, T., Chou, R., \& Kroner, K. (1992). ARCH modelling in finance: A review of the theory and empirical evidence. Journal of Econometrics, 52. https://doi.org/10.1016/0304-4076(92)90064-X 
Cheteni, P. (2017). Stock market volatility using GARCH models: evidence from South Africa and China stock markets. Journal of Economics and Behavioural Studies, 6. Retrieved March 19, 2018, from https://mpra.ub.uni-muenchen.de/77355/

Cont, R. (2005). Volatility clustering in financial markets: empirical facts and agent-based models. Long Memory in Economics. https://doi.org/10.2139/ssrn.1411462

Crouhy, M., \& Rockinger, M. (1997). Volatility clustering, asymmetry and hysteresis in stock returns: international evidence. Financial Engineering and the Japanese Market, 4. https://doi.org/10.1023/A:1009635408094

Dudukovic, S. (2014). A cumulant-based stock market volatility modelling - evidence from the international stock market. Journal of Finance and Accountancy, 17. Retrieved March 20, 2018, from http://www.aabri.com/manuscripts/141970.pdf

Fabozzi, F., Tunaru, R., \& Wu, T. (2004). Modelling volatility for the Chinese equity markets. Annals of Economics and Finance, 5. Retrieved March 17, 2018, from https://ideas.repec.org/a/cuf/journl/y2004v5i1p79-92.html

Friedmann, \& Sanddorf-Khole. (2002). Volatility clustering and nontrading days in Chinese stock markets. Journal of Economics and Business, 54. https://doi.org/10.1016/S0148-6195(01)00062-5

Gatheral, J. (2002). Lecture 1: Stochastic volatility and local volatility. Case studies in financial modelling courses notes. Merrill Lynch: Courant Institute of Mathematical Sciences. Retrieved April 10, 2018, from http://www.math.ku.dk/ rolf/teaching/ctff03/Gatheral.1.pdf

Granger, C., \& Machina, M. (2006). Structural attribution of observed volatility clustering. Journal of Econometrics, 135. Retrieved April 11, 2018, from http://econweb.ucsd.edu/ mmachina/papers/Granger-Machina_Volatility_Clustering.pdf

Ivanoski, Z., Stojanovski, T., \& Narasanov, Z. (2015). Volatility and kurtosis of daily stock returns at MSE. UTMS Journal of Economics, 6.

Karunanithy, B., \& Ramachandran, A. (2015). Modelling stock market volatility: evidence from India. Managing Global Transitions, 13.

Ljung, G., \& Box, G. E. (1978). On a measure of lack of fit in time series models. Biometrika, 66. https://doi.org/10.1093/biomet/65.2.297

Lux, T., \& Maechesi, M. (2000). Volatility clustering in financial markets: a microsimulation of interacting agents. International Journal of Theoretical and Applied Finance, 3(4). https://doi.org/10.1142/S0219024900000826

Mandelbrot, B. B. (1963). The variation of certain speculative prices. The Journal of Business, 36(4).

MSCI. (2008). China A-shares inclusion. Implementation $Q \& A$. Retrieved April 10, 2018, from https://www.msci.com/documents/1296102/1330218/CNA_Incl_QA.pdf/acc8b584-ccec-4483-958f-fc2f558ddb 1a

Niyitegeka, O., \& Tewari, D. D. (2013). Volatility clustering at the Johannesbourg Stock Exchange: Investigation and analysis. Mediterranean Journal of Social Science, 4(14). Retrieved May 5, from https://pdfs.semanticscholar.org/dd3c/1c996d740ea56ef994229398bcbf2a2bc70c.pdf

Wang, P., Wang, P., \& Liu, A. (2005). Stock return volatility and trading volume: evidence from the Chinese stock market. Journal of Chinese Economic and Business Studies, 3. https://doi.org/10.1080/14765280500040518

Lin, P., \& Fuerst, F. (2014). Volatility clustering, risk return relationship and asymmetric adjustment in the Canadian housing market. Journal of Real Estate Portfolio Management, 20(1). Retrieved March 17, 2018, from http://aresjournals.org/doi/abs/10.5555/repm.20.1.3205h51334r67148?code=ares-site

Stoffer, D., \& Toloi, C. (1992). A note on the Ljung-Box-Pierce portmantenau statistic with missing data. Statistics \& Probability Letters, 13(5). https://doi.org/10.1016/0167-7152(92)90112-I

Tripathi, V., \& Chaushary, P. (2016). Estimating stock return volatility in Indian and Chinese stock market. International Journal of Banking, Risk and Insurance, 4. Retrieved from https://ssrn.com/abstract=2828012 